\title{
Posterior Pituitary Hormones and Pain
}

\author{
Takanori MATSUURA ${ }^{1,2}$, Makoto KAWASAKI ${ }^{2}$, Akinori SAKAI ${ }^{1}$, and Yoichi UETA ${ }^{1, *}$ \\ ${ }^{1}$ Department of Physiology, School of Medicine, University of Occupational \\ and Environmental Health, Kitakyushu 807-8555, Japan \\ ${ }^{2}$ Department of Orthopaedics, School of Medicine, University of Occupational \\ and Environmental Health, Kitakyushu 807-8555, Japan
}

Received June 30, 2015; final version accepted July 23, 2015

\begin{abstract}
Vasopressin and oxytocin are well-known neurohypophysial and posterior pituitary hormones that are synthesized in the paraventricular and supraoptic nuclei of the hypothalamus and are secreted from the posterior pituitary into the systemic circulation. It is known that vasopressin plays an important role in maintaining body fluid homeostasis, and that oxytocin plays an essential role in mammalian labor and lactation through its peripheral action. In addition to these classic physiological actions, vasopressin and oxytocin have been attracting considerable attention in recent years because of their effects in their involvement in social recognition, and in the regulation of the cardiovascular system, the central nervous system and stress responses. Their analgesic effects have also been mentioned among these newly-recognized physiological actions. This review focuses on pain modulation by vasopressin and oxytocin.
\end{abstract}

KEYWORDS: pain, vasopressin, oxytocin

\section{Introduction}

Vasopressin and oxytocin are two well-known posterior pituitary hormones. Studies of these two hormones have a long history. Vasopressin was discovered in 1895 when a substance extracted from the bovine pituitary gland was found to have vasopressor and vasoconstrictor actions, and this substance was thus named "vaso (blood vessels) + press (pressure) + in" (vasopressin), based on its physiological actions [1]. Subsequently, this extract was shown to have an antidiuretic action, and this is why the extract is also referred to as antidiuretic hormone.

Oxytocin was discovered in 1906 as a substance promoting the processes of pregnancy and delivery. Because of its strong constrictive action, it was named "oxy (quick) + tocin (delivery)" (oxytocin) [2]. Both are peptide hormones consisting of nine amino acids, and seven of these amino acids are common. In 1953-54, du Vigneaud succeeded in determining the chemical structures and biosynthesis of vasopressin and oxytocin, and received the Nobel Prize in Chemistry (1955).

\section{Structures and secretory mechanisms of posterior pituitary hormones}

\subsection{Vasopressin}

Vasopressin consists of nine amino acids (Cys-Tyr-Phe-Gln-Asn-Cys-Pro-Arg-Gly-NH $\mathrm{N}_{2}$ ), has cysteine (Cys) as the first and sixth amino acids in the amino acid sequence, and has a cyclic structure with disulfide (S-S) bonds. However, this cyclic structure is not necessarily essential for binding to the receptor.

Vasopressin is produced in the neurosecretory neurons in the paraventricular nucleus, the supraoptic nucleus and its surrounding areas, and in the suprachiasmatic nucleus of the hypothalamus. The tissue distribution of vasopressin, as confirmed by immunohistochemical staining, is localized in the pineal body, spleen, adrenal glands, testes, and ovaries.

Vasopressin that is produced in magnocellular neurosecretory neurons of the paraventricular nucleus and the supraoptic nucleus is delivered inside axons projecting into the posterior pituitary by axonal flow to nerve endings, and stored in secretory granules. Vasopressin in vesicles in axon terminals is exocytosed in blood vessels in the posterior pituitary, and is delivered to target organs (organs having vasopressin receptors $\left(\mathrm{V}_{1 \mathrm{a}}, \mathrm{V}_{1 \mathrm{~b}}\right.$ and $\left.\mathrm{V}_{2}\right)$ ) via the bloodstream. Secretion of vasopressin from the nerve endings is basically controlled by increased and decreased action potentials generated in the magnocellular neurosecretory neurons. In recent years, it has been revealed that vasopressin generated in the magnocellular neurosecretory neurons is also exocytosed from cell bodies and dendrites [3]. This secretion is referred to as somato-dendritic release, and the physiological action in the brain of vasopressin secreted by autocrine and paracrine mechanisms has been attracting research attention. This secretion has been verified by electron 
microscopic imaging of the exocytosis of synaptic vesicles and the detection of vasopressin in extracellular fluids, but its characteristics are different from those of secretion from the posterior pituitary, such as the absence of dependence on action potentials and the necessity of sufficient elevation of intracellular $\mathrm{Ca}^{2+}$.

\subsection{Oxytocin}

Oxytocin consists of nine amino acids (Cys-Tyr-lle-Gln-Asn-Cys-Pro-Leu-Gly-NH $\mathrm{NH}_{2}$ ). Like vasopressin, it has cysteine (Cys) as the first and sixth amino acids, has a cyclic structure with disulfide (S-S) bonds, and its structure is very similar to that of vasopressin. Vasopressin and oxytocin genes are present on the human 20 th chromosome (20 p 13 , second chromosome in mice), facing each other. Both the vasopressin and the oxytocin gene consist of 3 exons and 2 introns, and these hormones are generated as a result of separation from prohormones consisting of oxytocin and neurophysin I or vasopressin and neurophysin II [4].

Oxytocin is also produced in magnocellular neurosecretory neurons in the paraventricular nucleus and supraoptic nucleus, and is delivered to the posterior pituitary, exocytosed in blood vessels, and then delivered to target organs (organs having oxytocin receptors [OTR]). Under ordinary conditions, the cell bodies producing vasopressin and oxytocin are different, and magnocellular neurosecretory neurons containing both peptides are rare. It has been suggested that vasopressin like oxytocin is secreted by cell bodies and dendrites [3].

\section{Receptors of posterior pituitary hormones}

\subsection{Vasopressin receptors}

Vasopressin receptors include $\mathrm{V}_{1 \mathrm{a}}, \mathrm{V}_{1 \mathrm{~b}}$, and $\mathrm{V}_{2}$ receptors, and all of them are seven-pass transmembrane $\mathrm{G}$ proteincoupled receptors. The $G$ protein is a Gaq protein for the $V_{1 a}$ and $V_{1 b}$ receptors, and a Gas protein for the $V_{2}$ receptor. $\mathrm{V}_{1 \mathrm{a}}$ receptors are localized in the central nerves as well as in the vascular smooth muscles and liver in the periphery, and are involved in vasoconstrictor and hepatic glycogenolytic actions. $\mathrm{V}_{1 \mathrm{~b}}$ receptors are distributed in the anterior pituitary and promote adrenocorticotropic hormone $(\mathrm{ACTH})$ secretion. $\mathrm{V}_{2}$ receptors are involved in the antidiuretic action in the renal collecting duct. The projection of vasopressin neurons to the olfactory bulb [5], to the locus coeruleus as the nuclei of origin of noradrenergic neurons [6], and to the rostral ventrolateral medulla in the autonomic nervous region and the spinal cord has been reported [7], and it is assumed that there are physiological actions mediated by the vasopressin receptor $\left(\mathrm{V}_{1 \mathrm{a}}\right)$ are assumed.

\subsection{Oxytocin receptors}

Like vasopressin receptor, OTR are seven-pass transmembrane G protein-coupled receptors, and are coupled with trimer-type $\mathrm{G}$ protein $\mathrm{G} \alpha \mathrm{q} / 11$ and Gi. Among the peripheral organs, oxytocin receptors are present in the uterine muscles, mammary glands, ovaries, vagina, Leydig cells of the testis, kidneys, and heart. In the central nervous system, they are present in the olfactory bulb, cerebral cortex, basal ganglia, limbic system, thalamus, hypothalamus, central gray matter, and raphe nuclei [8]. Oxytocin is also produced in the cell bodies of parvocellular neurosecretory neurons in the paraventricular nucleus of the hypothalamus, and some of these neurons project their axons into the preganglionic sympathetic neurons in the brainstem and the spinal cord, and are involved in the adjustment of autonomic nerve functions in the brainstem and spinal cord mediated by OTR [9].

When oxytocin binds to OTR, diacylglycerol (DG) and inositol 1,4,5-3 phosphate (IP3) are generated from phosphatidyl inositol 2 phosphate (PIP2), DG activates protein kinase C (PKC), and IP3 increases intracellular Ca ${ }^{2+}$ concentrations through IP3 receptors in the endoplasmic reticulum. Moreover, cyclic ADP rebose is reportedly generated at the same time, and binds to CD38 [10].

\section{Physiological roles of pituitary hormones (classic)}

\subsection{Vasopressin}

Vasopressin acts on vascular smooth muscles through $\mathrm{V}_{1 \mathrm{a}}$ receptors to induce vasoconstriction. It also has an antidiuretic action, inducing water reabsorption in the renal collecting duct via vasopressin $\mathrm{V}_{2}$ receptors. These are the two main actions of vasopressin, and this hormone plays an important role in maintaining body fluid homeostasis. The major factor stimulating the secretion of vasopressin is the elevation of the osmotic pressure of body fluids, as perceived by the osmotic pressure receptors in the hypothalamus. The decrease in blood volume perceived by baroreceptors in the right atrium, the pulmonary vein, the carotid sinus, and the aortic arch is also an important stimulus for vasopressin secretion. The signal indicating decreased blood volume is transmitted to the central nervous system via the vagus nerve and the glossopharyngeal nerve.

\subsection{Oxytocin}

With respect to the physiological actions of oxytocin, when sensory information from the periphery (stimulation to extend the orifice of the uterus induced by engagement of the fetal head, and stimulation induced by an infant sucking on the nipples) enters the nervous system in the late stage of delivery or the lactation period, oxytocin neurons are 
synchronized and excited in the form of a burst, and oxytocin is secreted from the axon terminals projecting into the posterior pituitary into circulating blood. The major physiological actions in the periphery are uterine muscle contraction at the time of delivery and milk ejection during the lactation period. Additional known functions of oxytocin are the regulation of luteal functions, transport of eggs, contraction of spermatic ducts, metabolic regulation of water and electrolytes, and promotion of the secretion of atrial sodium diuretic peptide.

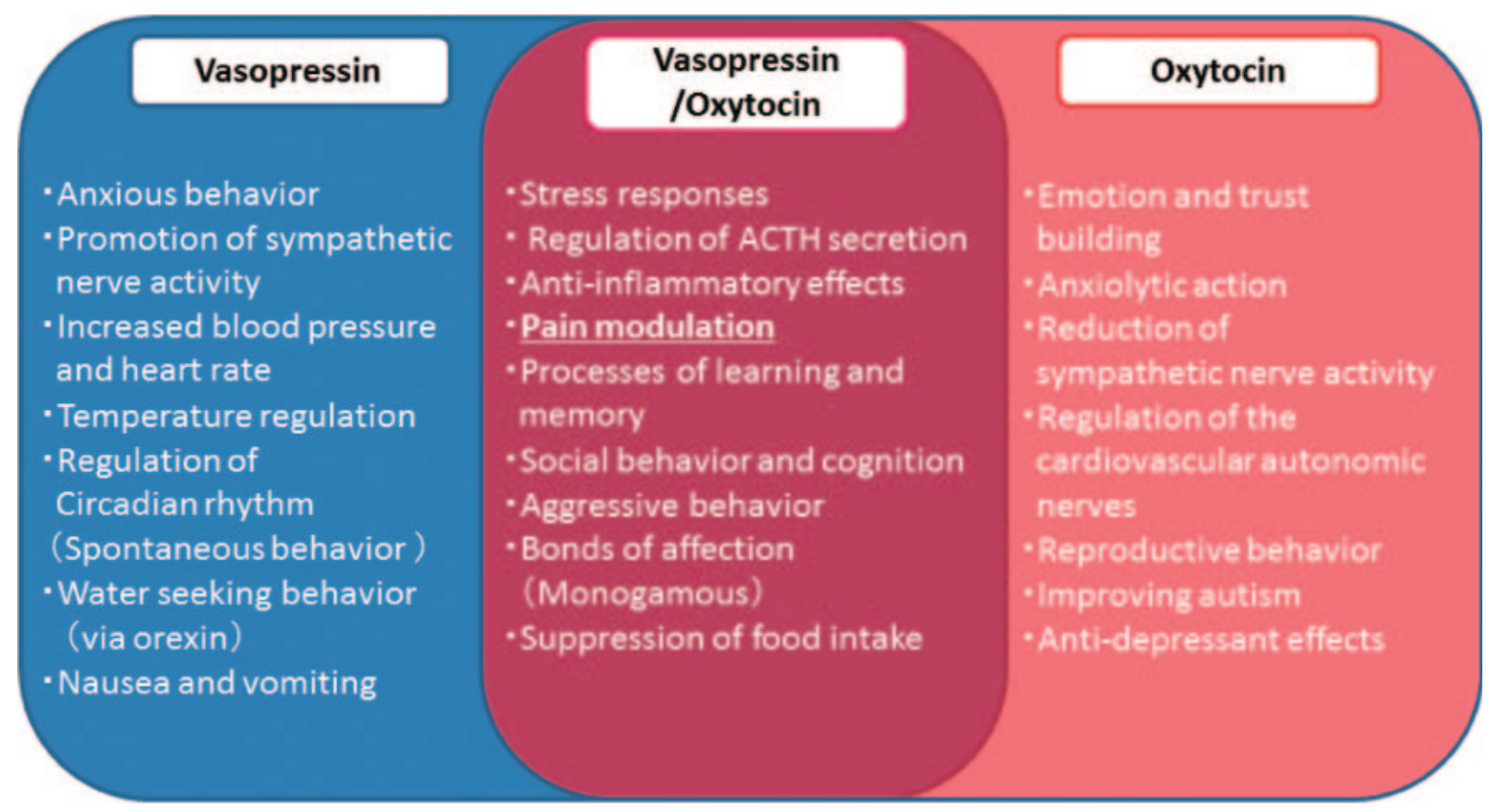

Fig. 1. Vasopressin and oxytocin's actions on the central nervous system.

\section{Relationship between posterior pituitary hormones and pain}

In addition to these classic physiological actions, vasopressin and oxytocin have been attracting considerable attention in recent years because of their effects in an extensive range of processes, including those of learning and memory, and their involvement in social recognition and the regulation of the cardiovascular system, central nervous system and stress responses [5, 8,11$]$. Analgesic effects have also been mentioned as newly-recognized physiological actions. To date, the analgesic effects of oxytocin and vasopressin have been reported in humans and rodents [12, 13]. The targets of axons projecting into the vasopressin and oxytocin neurons in the hypothalamus are extensively distributed in the central nerves in the hypothalamus, which is associated with perception and pain threshold [14]. In particular, oxytocin neurons project into the thalamus, central gray matter, nigrostriatal system, locus coeruleus, nucleus of the solitary tract, and the spinal cord [15]. Intracerebral administrations of oxytocin and vasopressin have been reported to exert analgesic effects in various pain tests [16, 17].

\subsection{Vasopressin and pain}

Recent studies suggest that vasopressin directly activates central vasopressin receptors in response to nociception, and also exerts actions mediated by the receptors present in peripheral tissues. Interactions between antinociceptive actions and the vasopressin system have been studied in mutant Brattleboro rats lacking vasopressin, as well as in vasopressin receptor $\left(\mathrm{V}_{1 \mathrm{a}}, \mathrm{V}_{1 \mathrm{~b}}, \mathrm{~V}_{2}\right)$ gene knockout mice. Brattleboro rats exhibit hyperesthesia as compared with wild rats, and dependent on vasopressin, and to be ameliorated by Vasopressin administration [18]. In an experiment comparing $\mathrm{V}_{1 \mathrm{a}}$ and $\mathrm{V}_{1 \mathrm{~b}}$ knockout mice, $\mathrm{V}_{1 \mathrm{a}}$ receptors were found to be associated with hypoesthesia in response to temperature stimulation and $\mathrm{V}_{1 \mathrm{~b}}$ receptors were associated with hyperesthesia in response to temperature stimulation [12]. In another study, vasopressin was found to impact the pain threshold, mainly via $\mathrm{V}_{1 \mathrm{a}}$ receptors, and to activate the phospholipase $\mathrm{C} \beta$ (PLC $\beta$ ) pathway [19].

An association with opioids has also been suggested as an explanation of the analgesic actions of vasopressin. $V_{1 b}$ receptors inhibit the analgesic responses induced by morphine, while $\mathrm{V}_{1 \mathrm{~b}}$ receptors are involved in the nerve network in the dopamine system of the mesolimbic system, and are considered to play important roles in regulating the acceleration of locomotor activity and hypothermia induced by morphine [13]. Recent studies have suggested that an opioid receptor antagonist, naloxone, inhibits the antinociceptive action induced by vasopressin [20]. On the other hand, another study found that the antinociceptive action of vasopressin was not affected by opioids [21]. The details of this mechanism remain unknown. 
Vasopressin is also involved in the hypothalamic-pituitary axis, which serves as the main axis of the endocrine response to stressors. Among the neurosecretory neurons in the parvocellular region of the paraventricular nucleus, the neurons that produce corticotrophin-releasing hormone $(\mathrm{CRH})$ also produce vasopressin. Like $\mathrm{CRH}$, the vasopressin produced is secreted into the hypophyseal portal vein, which runs from the outside of the median eminence toward the pituitary, and acts on the anterior pituitary to stimulate the secretion of ACTH. ACTH secretion exhibits larger synergistic effects when $\mathrm{CRH}$ and vasopressin act simultaneously than with either hormone acting independently, i.e. after CRH alone or vasopressin alone [22]. In an animal model of chronic pain and inflammation, these was an increase in vasopressin production in the magnocellular neurosecretory neurons in addition to that in the parvocellular neurosecretory neurons of the paraventricular nucleus, and an increase in vasopressin secretion from the posterior pituitary [23]. The increases in vasopressin production and secretion are not dependent on plasma osmotic pressures or sodium concentrations, and are deemed to be involved in some form of pain control, although their actual roles are unknown.

\subsection{Oxytocin and pain}

Numerous reports have focused on the involvement of oxytocin in nociception, and these networks are still being actively studied. In recent years, a highly sensitive method for detecting OTR has been developed, and the sites of OTR expression in the spinal cord have been reported to be laminae I-II, intermediomedial/intermediolateral grey matter, lamina $X$, the parasympathetic nerve region, and the dorsal root ganglion in rats [24, 25]. In particular, it is suggested that OTR is abundant in the dorsal horn (laminae I-II) of the spinal cord, which is associated with nociception.

Two pathways have been suggested as the mechanisms of nociception associated with oxytocin. The first pathway is the one in which the axons of magnocellular neurosecretory neurons localized in the paraventricular nucleus and in the supraoptic nucleus project into the posterior pituitary; in this pathway, oxytocin is secreted from the posterior pituitary into circulating blood, and the oxytocin in the circulating blood then acts on the dorsal root ganglion to influence nociception. The second pathway is the one in which oxytocin produced in parvocellular neurosecretory neurons of the paraventricular nucleus plays a direct role in the central nervous system, which is the target of projection. Pathways acting on each neuromere level of the central nervous system and spinal cord have been suggested, but the details are as yet unknown.

Presynaptic activation of spinal interneurons in the inhibitory system and activation of the PLC $\beta$ signaling pathway have been suggested as mechanisms of action by which oxytocin induces analgesia in the spinal cord [26]. It has been suggested that amplification of GABAergic neurons in the inhibitory system induces oxytocin's selective inhibition of excitability in the spinal cord, and the pain transmitted from the periphery to the dorsal horn of the spinal cord by this action may be attenuated at the spinal cord level [27].

Like oxytocin and vasopressin, oxytocin receptors and $\mathrm{V}_{1 \mathrm{a}}$ receptors exhibit very high sequence homology. Therefore, both peptides are thought to be able to activate both receptors. In a study using two mouse strains, i.e., OTR and $\mathrm{V}_{1 \mathrm{a}}$ receptor knockout mice, analgesia induced by oxytocin was reportedly normal in the oxytocin receptor knockout mice but was absent in the $\mathrm{V}_{1 \mathrm{a}}$ receptor knockout mice. These results suggest that $\mathrm{V}_{1 \mathrm{a}}$ receptors mediated the actions of the OXT. Moreover, similar findings were obtained when selective antagonists for oxytocin receptors and $\mathrm{V}_{1 \mathrm{a}}$ receptors were used, suggesting that the analgesia induced by an oxytocin is regulated by $\mathrm{V}_{1 \mathrm{a}}$ receptors present in the dorsal root ganglion (DRG) [28].

With respect to the association between oxytocin and opioids, inhibition of the oxytocin-induced analgesic effect by naloxone, and inhibition of the secretion of oxytocin by an endogenous opioid in late pregnancy have been reported [29]. Dynorphin coexists in magnocellular neurosecretory neurons producing vasopressin and oxytocin, and the nerve endings in the posterior pituitary also contain enkephalin peptide in addition to vasopressin and oxytocin. Opioid peptides coexisting with vasopressin and oxytocin may be secreted simultaneously in the posterior pituitary and in the central nervous system.

Oxytocin has also been reported to be involved in the hypothalamic-pituitary axis, which, as mentioned above, is the main axis serving in the endocrine response to stress [30]. Furthermore, intracerebral administration of oxytocin is deemed to inhibit CRH mRNA expression in the hypothalamic paraventricular nucleus in response to stressful stimuli, and to attenuate ACTH release and corticosterone release.

Our recent study demonstrated that an oxytocinergic pathway from the PVN may be involved in pain modulation in a chronic inflammatory stress model (adjuvand arthritic rat) [31].

\section{Neuropeptides and pain}

The mechanism of the action of neuropeptides, for which an association with pain has been suggested, has received research attention. Representative peptides associated with pain include substance P (SP), calcitonin gene-related peptide (CGRP), opioid peptide, somatostatin, and vasoactive intestinal peptide. In recent years, associations with pain have been reported for posterior pituitary hormones, as discussed in this article, as well as nociceptin, nocistatin, and orexin. 
SP is produced in the cell bodies of the primary sensory neurons of the DRG, and is transported to the central and peripheral sites of the primary sensory neurons. CGRP is extensively distributed in the central nervous system, peripheral nervous system and peripheral tissues. Like SP, CGRP is thought to induce both inflammatory and neuropathic pain. The opioid peptides that induce the actions of morphine, which are presently well-known pain controllers, are extensively distributed in the central nervous system. Representative endogenous opioid peptides include enkephalin, dynorphin, and endorphin. They are bound to $\delta, \mu$, and $\kappa$ receptors, respectively, thereby exhibiting morphine-like actions. Opioids inhibit the release of neurotransmitters in the primary sensory nerve endings (presynaptic inhibition), and inhibit membrane excitability in the dorsal horn of the spinal cord (postsynaptic inhibition), thereby inhibiting transmission of pain to the brain, and playing a role in the activation of the descending inhibitory system.

Precursors of nociceptin and nocistatin are extensively localized in the brain (e.g. the brainstem), and in the spinal cord (e.g. the dorsal horn). Nociceptin may induce hyperalgesia in the brain and spinal cord, while nocistatin is believed to inhibit hyperalgesic responses and inflammatory pain. As to orexin, orexin-producing neurons are localized in the lateral hypothalamic field and surrounding area, and their axons project to various central nerve nuclei. Fibers containing orexin are abundant in one layer of the dorsal horn of the spinal cord. Orexin is transported from the hypothalamus to the superficial layer, especially the first layer, of the dorsal horn of the spinal cord, and is believed to innervate $\mathrm{C}$ fibers, which are associated with noxious stimulus transmission. Analgesic effects have been obtained after systemic, intraventricular, and intrathecal administrations of orexin in various pain models.

Neuropeptides, including the posterior pituitary hormones which are the subject of this article, are attracting attention as a novel target of pain control. These neuropeptides are expected to become new targets of research and in the development of analgesics for effectively treating intractable pain.

\section{Conclusion}

In this article we discussed the fundamental aspects of the physiological roles of the posterior pituitary hormones vasopressin and oxytocin in secretory regulation and nociception. Both hormones were discovered more than 100 years ago, but are still actively studied in various fields. In essence, they are old and new peptide hormones. Further elucidation of the molecular basis of their physiological roles, including pain mechanisms, is anticipated from future research.

\section{Acknowledgments}

This work was supported by a Grants-in-Aid for Scientific Research (B), No. 25293055, to Y.U, (C), No. 25462391, to M.K. from the Japan Society for the Promotion of Science (JSPS), Japan, and a University of Occupational and Environmental Health Research Grant for the Promotion of Occupational Health to M.K. We thank Carman Christopher P. for critically reading and editing the language in the manuscript. Disclosure of Summary: The authors have nothing to disclose.

\section{REFERENCES}

[1] Oliver G, Schafer EA (1895) On the Physiological Action of Extracts of Pituitary Body and certain other Glandular Organs: Preliminary Communication. The Journal of physiology 18:277-279.

[2] Dale HH (1906) On some physiological actions of ergot. The Journal of physiology 34:163-206.

[3] Gimpl G, Fahrenholz F (2001) The oxytocin receptor system: structure, function, and regulation. Physiol Rev 81:629-683.

[4] Ludwig M, Leng G (2006) Dendritic peptide release and peptide-dependent behaviours. Nature reviews Neuroscience 7:126-136.

[5] Brownstein MJ, Russell JT, Gainer H (1980) Synthesis, transport, and release of posterior pituitary hormones. Science 207:373-378.

[6] Tobin VA, Hashimoto H, Wacker DW, Takayanagi Y, Langnaese K, Caquineau C, Noack J, Landgraf R, Onaka T, Leng G, Meddle SL, Engelmann M, Ludwig M (2010) An intrinsic vasopressin system in the olfactory bulb is involved in social recognition. Nature 464:413-417.

[7] Caffe AR, van Leeuwen FW, Buijs RM, de Vries GJ, Geffard M (1985) Coexistence of vasopressin, neurophysin and noradrenaline immunoreactivity in medium-sized cells of the locus coeruleus and subcoeruleus in the rat. Brain Res 338:160-164.

[8] Swanson LW, Sawchenko PE (1980) Paraventricular nucleus: a site for the integration of neuroendocrine and autonomic mechanisms. Neuroendocrinology 31:410-417.

[9] Striepens N, Kendrick KM, Maier W, Hurlemann R (2011) Prosocial effects of oxytocin and clinical evidence for its therapeutic potential. Front Neuroendocrinol 32:426-450.

[10] Sofroniew MV (1980) Projections from vasopressin, oxytocin, and neurophysin neurons to neural targets in the rat and human. J Histochem Cytochem 28:475-478.

[11] Lopatina O, Liu HX, Amina S, Hashii M, Higashida H (2010) Oxytocin-induced elevation of ADP-ribosyl cyclase activity, cyclic ADP-ribose or $\mathrm{Ca}(2+)$ concentrations is involved in autoregulation of oxytocin secretion in the hypothalamus and posterior pituitary in male mice. Neuropharmacology 58:50-55. 
[12] Carter CS, Boone EM, Pournajafi-Nazarloo H, Bales KL (2009) Consequences of early experiences and exposure to oxytocin and vasopressin are sexually dimorphic. Dev Neurosci 31:332-341.

[13] Honda K, Takano Y (2009) New topics in vasopressin receptors and approach to novel drugs: involvement of vasopressin V1a and V1b receptors in nociceptive responses and morphine-induced effects. Journal of pharmacological sciences 109:38-43.

[14] Koshimizu TA, Tsujimoto G (2009) New topics in vasopressin receptors and approach to novel drugs: vasopressin and pain perception. Journal of pharmacological sciences 109:33-37.

[15] Watson SJ, Seidah NG, Chretien M (1982) The carboxy terminus of the precursor to vasopressin and neurophysin: immunocytochemistry in rat brain. Science 217:853-855.

[16] Gimpl G, Fahrenholz F (2001) The oxytocin receptor system: structure, function, and regulation. Physiol Rev 81:629-683.

[17] Bodnar RJ, Zimmerman EA, Nilaver G, Mansour A, Thomas LW, Kelly DD, Glusman M (1980) Dissociation of cold-water swim and morphine analgesia in Brattleboro rats with diabetes insipidus. Life Sci 26:1581-1590.

[18] Miranda-Cardenas Y, Rojas-Piloni G, Martinez-Lorenzana G, Rodriguez-Jimenez J, Lopez-Hidalgo M, Freund-Mercier MJ, Condes-Lara M (2006) Oxytocin and electrical stimulation of the paraventricular hypothalamic nucleus produce antinociceptive effects that are reversed by an oxytocin antagonist. Pain 122:182-189.

[19] Bodnar RJ, Wallace MM, Kordower JH, Nilaver G, Cort J, Zimmerman EA (1982) Modulation of nociceptive thresholds by vasopressin in the Brattleboro and normal rat. Ann N Y Acad Sci 394:735-739.

[20] Schoneberg T, Kostenis E, Liu J, Gudermann T, Wess J (1998) Molecular aspects of vasopressin receptor function. Adv Exp Med Biol 449:347-358.

[21] Yang J, Yang Y, Xu HT, Chen JM, Liu WY, Lin BC (2006) Arginine vasopressin enhances periaqueductal gray synthesis and secretion of enkephalin and endorphin in the rat. Brain Res Bull 71:193-199.

[22] Kordower JH, Bodnar RJ (1984) Vasopressin analgesia: specificity of action and non-opioid effects. Peptides 5:747-756.

[23] Volpi S, Rabadan-Diehl C, Aguilera G (2004) Vasopressinergic regulation of the hypothalamic pituitary adrenal axis and stress adaptation. Stress 7:75-83.

[24] Suzuki H, Kawasaki M, Ohnishi H, Nakamura T, Ueta Y (2009) Regulatory mechanism of the arginine vasopressin-enhanced green fluorescent protein fusion gene expression in acute and chronic stress. Peptides 30:1763-1770.

[25] Moreno-Lopez Y, Martinez-Lorenzana G, Condes-Lara M, Rojas-Piloni G (2013) Identification of oxytocin receptor in the dorsal horn and nociceptive dorsal root ganglion neurons. Neuropeptides 47:117-123.

[26] Rojas-Piloni G, Mejia-Rodriguez R, Martinez-Lorenzana G, Condes-Lara M (2010) Oxytocin, but not vassopressin, modulates nociceptive responses in dorsal horn neurons. Neurosci Lett 476:32-35.

[27] Ku CY, Qian A, Wen Y, Anwer K, Sanborn BM (1995) Oxytocin stimulates myometrial guanosine triphosphatase and phospholipase-C activities via coupling to $\mathrm{G}$ alpha q/11. Endocrinology 136:1509-1515.

[28] Breton JD, Veinante P, Uhl-Bronner S, Vergnano AM, Freund-Mercier MJ, Schlichter R, Poisbeau P (2008) Oxytocin-induced antinociception in the spinal cord is mediated by a subpopulation of glutamatergic neurons in lamina I-II which amplify GABAergic inhibition. Molecular pain 4.

[29] Schorscher-Petcu A, Sotocinal S, Ciura S, Dupre A, Ritchie J, Sorge RE, Crawley JN, Hu SB, Nishimori K, Young LJ, Tribollet E, Quirion R, Mogil JS (2010) Oxytocin-induced analgesia and scratching are mediated by the vasopressin-1A receptor in the mouse. J Neurosci 30:8274-8284.

[30] Russo R, D’Agostino G, Mattace Raso G, Avagliano C, Cristiano C, Meli R, Calignano A (2012) Central administration of oxytocin reduces hyperalgesia in mice: implication for cannabinoid and opioid systems. Peptides 38:81-88.

[31] Neumann ID (2002) Involvement of the brain oxytocin system in stress coping: interactions with the hypothalamo-pituitaryadrenal axis. Prog Brain Res 139:147-162.

[32] Matsuura T, Kawasaki M, Hashimoto H, Ishikura T, Yoshimura M, Ohkubo JI, Maruyama T, Motojima Y, Sabanai K, Mori T, Ohnishi H, Sakai A, Ueta Y (2015) Fluorescent visualisation of oxytocin in the hypothalamo-neurohypophysial/-spinal pathways after chronic inflammation in oxytocin-mRFP1 transgenic rats. J Neuroendocrinol. 